\title{
The Patient Protection and Affordable Care Act
}

\section{Legal Analysis and Moral Judgment at the United States Conference of Catholic Bishops*}

\section{Anthony R. Picarello Jr., J.D.}

\begin{abstract}
At the time that the Patient Protection and Affordable Care Act was being debated in Congress, the United States Conference of Catholic Bishops took great care in its response to the act. This article describes some of the internal legal issues raised at the USCCB that informed the bishops' ultimate moral opposition to the act. In short, the issues were the threats to conscience contained in the bill, how the bill addresses coverage for illegal immigrants, and whether the bill would fund abortion. While the debate about abortion funding captured almost all of the media attention, all three of these considerations informed the position of the bishops that the bill should be opposed. The reasoning behind each concern is discussed as well as the respective roles of the lawyers, analysts, and bishops in reaching the conclusion.
\end{abstract}

\section{Introduction}

The health-care reform law, or more formally the Patient Protection and Affordable Care Act (PPACA), is so vast that almost no one can

\footnotetext{
* Address given at the Archdiocese of Baltimore's Third Annual Symposium for Catholic Medical Professionals, "Health Care Reform and the Catholic Medical Professional," St. Joseph Medical Center, Towson, MD, March 12, 2011.
}

The Linacre Quarterly 79(3) (August 2012): 338-352.

(C) 2012 by the Catholic Medical Association. All rights reserved. o024-3639/2012/7903-0010 \$.30/page. 
claim to understand it fully. But there is a slice of it that some have tried very hard to understand, and those are the parts that generate moral questions of particular concern to the Catholic bishops of the United States. Ultimately, the bishops were left in a bad position: they had to oppose the bill, despite a general interest in wanting to see health-care reform including universal health coverage, because of considerations associated with immigration, conscience, and abortion funding. It is worthwhile to try to unpack these issues a little in order to clarify what informed the bishops' decision making. But it is also useful to move beyond the nuts and bolts of who may be right and wrong legally on these disputed issues and address as well the moral component of the analysis, and more precisely, who should be making that moral analysis. This is useful as a contribution to the ongoing debate about the respective roles of bishops and laypeople in the United States Conference of Catholic Bishops' (USCCB's) moral analysis of laws and policies.

In describing the legal contours of PPACA's moral problems, I will first describe the problems other than abortion funding-conscience protection outside the abortion context and justice for immigrantsbecause they so often get short shrift. Then I will discuss abortion funding and the persistent doubts about that. This analysis reflects not only the debate as the law was being considered, but also some of the subsequent experience in the short time since the law passed that tends to confirm the view that in fact the bill does tend to fund abortion.

\section{Mandates that Threaten Conscience}

The core conscience problem with PPACA is that it contains various new mandates to provide coverage for certain procedures, but does not provide any corresponding exemptions to accommodate conscience. This problem finds expression at every level in the health-care insurance "food chain," as it were: the insurers, the plan sponsors, the employers, the plan purchasers, and the individual insured employees. The coverage mandates of PPACA empower the government to use its coercive power to force these various stakeholders, in their respective roles, to facilitate the provision of a medical "service" that they might consider immoral.

The straightforward solution to the threat to conscience is just to allow insurers (who are at the top of the "food chain") to make those accommodations when requested, just as they have been free to do until now. This is the current situation without the bill. Consider, for example, the person responsible for purchasing health insurance for the employees of the USCCB, who simply will not buy coverage for abortion, contraception, or anything else that would violate Catholic teaching. That person would go to a group of potential insurers, and say, "Write me up a policy that covers everything but these illicit things." The USCCB gets a few bids, picks the bid it wants, and everything is fine. 
You could call that an accommodation, but it is nothing more than the market at work; it is a buyer saying "I want this service, but not that service," and a seller voluntarily offering to meet that need. If a seller somehow feels obliged to include the illicit things in every single policy the seller offers, it is entirely free not to make a bid for the buyer's business. If there are somehow no sellers willing to omit the illicit service, that is the buyer's tough luck-but it is not a religious freedom problem, because there is no government coercion involved. Nobody is forced, everybody gets what they want, almost all the time-it is a win-win.

But now, an employer can no longer just go out into the market and say, "I want A, B, and C, but not D." The government dictates what their coverage has to provide, with no provision in the statute for conscientious objectors. Most often, when analogous mandates are proposed in other contexts, this risk to conscience is recognized and addressed. For example, concerning those with a bona fide religious objection, the law could provide that insurers remain free to deal with these employers in the way they otherwise would.

This is not a revolutionary idea; in fact, it is the opposite. An exception like that in the language of the statute would simply perpetuate the status quo in federal law, not alter it. That was the USCCB's proposal. But when we raised both the issue and the solution among policymakers, we were simply ignored. The bad news is that those dedicated to the passage of PPACA, regardless of its flaws, got away with ignoring the issue. This was possible mainly because so much attention was focused on the question of abortion funding. The good news is that the existence of this problem was never disputed. Unlike the abortion funding question, it did not divide the Catholic community. One hopes that this will mean unity when the problem eventually materializes. But one also wonders how those who knew earlier of the problem, but chose to ignore it entirely, will account later for their silence and inaction.

Unfortunately, it appears that we will not need to wait too long for this problem to materialize. One of the mandates is to provide what are called "preventive services." Properly understood, those services are good things, like mammograms and colonoscopies, because they are designed to identify diseases early and head them off. It even makes sense to make coverage of such services mandatory and co-pay free, because it provides an incentive to actually take advantage of these services. It is an embodiment of the wisdom that an ounce of prevention is worth a pound of cure. So far, so good.

But along comes Planned Parenthood to say that "preventive services" ought to include services to prevent pregnancy. The problem is that pregnancy is not a disease, so preventing it should not fall within the category of "preventive services," which otherwise do prevent diseases. ${ }^{1}$ It makes sense for government to incentivize the prevention of disease; it is positively disturbing for government to incentivize the prevention of people. ${ }^{2}$ The distortion of this particular mandate in this particular 
way was one of the particular problems with PPACA that the USCCB highlighted before the law was passed. ${ }^{3}$

And that is precisely the argument Planned Parenthood has made in the regulatory process, which is currently before the Institute of Medicine. They are lobbying hard for this at the Institute of Medicine hearings, and the USCCB is doing its best to push back within the constraints of the process. ${ }^{4}$ It is unclear how the language will ultimately be interpreted, but I am not optimistic. ${ }^{5}$

In any event, my broader point is to show that there is an overall structural problem in the statute-statutory mandates without corresponding statutory provisions for conscience. It is also to show that one instance of this broader problem is already beginning to emerge. This is not a case of lawyers being paranoid-this is real and is already starting to happen. Give it another six months, and we should be hearing some more.

\section{Justice for Immigrants}

Another moral problem that the bishops identified other than abortion funding involves justice for immigrants. There are two problems of this type. The first is that the bill prevents undocumented immigrants from buying insurance with their own funds, even without subsidy. As I understand it, the USCCB is comfortable with the idea that an undocumented person should not get the subsidy associated with health-care reform. Being documented or undocumented does have some important consequences, and that could legitimately be one of them. However, undocumented people in this country still get sick, they still show up at the hospitals, and they are still entitled to decent care. One version of the bill would have addressed this reality by giving undocumented people the option to pay their own way by purchasing insurance with their own funds.

One might expect that even those who are very hostile to immigration, whether legal or illegal, might like this policy because of their tendency to view immigrants as a drain on the system. And indeed, the House bill did contain the solution of allowing undocumented immigrants to purchase insurance for themselves without subsidy. However, this provision got stripped out in the Senate bill. As a result, you have a greater likelihood of two bad results: that undocumented persons will get less or lower-quality care (because fewer resources are available to pay for it) and that the cost of the care that they do get will be borne by the taxpayer. This creates a lose-lose situation.

There was a second problem regarding immigrants. Currently, someone who is legal and documented is prohibited from participating in Medicaid for five years. That is unfortunate, because they are legal and playing by the rules, but they still cannot get Medicaid for five years. An amendment to PPACA was proposed that would have removed this 
limitation on access to Medicaid. The bishops supported this amendment, but it was rejected in the Senate. ${ }^{6}$

The USCCB's statements during the fight over the law identified both of these problems of justice for immigrants. Unfortunately, as with the conscience problem, those in the Catholic community who were determined to support PPACA regardless of its flaws did not join with their bishops in taking up these issues.

\section{Abortion Funding}

The highest profile issue that caused the greatest controversy was abortion funding. First, I will describe specifically and legally why we did (and still do) expect that PPACA will fund abortions. ${ }^{7}$

When courts have interpreted statutory language that provides for very broad categories of health service that might include abortion, the courts typically read it to include abortion. For example, if a statute requires the funding of "women's health" or "family planning," courts consistently construe those statutes to require the funding of abortion. This kind of argument has been tested repeatedly in litigation with the same result. Importantly, although courts have said that they will construe broad statutory categories to include abortion, they have also said that Congress remains free to specify that abortion is excluded from those broad categories.

In other words, Congress can carve abortion out. It can set up broad health categories and say specifically, "But we don't want this to include abortion"-and the courts will respect that limitation. That is how the Hyde Amendment came into being. It was first instituted in the early to mid-1970s precisely because there were a series of judicial decisions that construed laws to fund abortion that were not intended to do so. So when the courts said that abortion would be funded absent express congressional exception, Congress responded by providing that express exception. That is the jurisprudential context for construing any health-care reform law down the road.

Along comes PPACA, and it provides broad categories of funded health care. In turn, it will be construed to fund abortion unless there are express exceptions. And there are, indeed, some express exceptions like this in PPACA, but they are limited in scope. PPACA is a notoriously lengthy bill, comprising thousands of pages. In this context, just about the only thing that would have worked-short of tracking down each and every particular mandate, and providing an abortion funding carve-out for each-would have been a law that said broadly, "Anything in this act-any funding stream, any dollars-may not be used to cover abortion." That was the Stupak Amendment: it was straightforward and clear, and it basically took the Hyde Amendment language-the same words, cut-and-paste-and would have applied them to all of the new funding streams of PPACA. Instead, what ended up happening was that 
there were certain particular carve-outs to certain particular funding streams, and even in those areas, the limitation on abortion funding was dubious at best. So now, there is a solution that is inadequate where it applies, and it applies to only a fraction of the overall abortion funding problem.

There is no need to speak only in the abstract about some possibility that there might be some funding stream somewhere in PPACA that is not covered-there is one funding stream in particular that is worth mentioning and represents a large amount of money. Over a period of ten years, PPACA appropriates around ten billion dollars for community health centers. The funding restrictions in the act simply do not cover this funding stream.

One may ask why the Hyde Amendment does not cover this funding stream. Does not that amendment already prohibit federal funds from paying for abortion? No, and the reason is that the Hyde Amendment is not a permanent statute, and it does not cover every federal dollar that is spent on health care. The Hyde Amendment is an annually renewed law called an appropriations rider. It is tacked on to particular annual appropriations every year, year after year. Every year, those of us at the USCCB have to fight to get the Hyde Amendment renewed. We have succeeded thirty-seven years in a row, but we have had to fight for it every single year. On top of that, it is tied to particular funding streams - the annual appropriations of the Department of Health and Human Services (HHS) and the Department of Labor. Although these two appropriations represent the two most relevant funding streams, they are not the only ones that might cover abortion. More relevantly here, Hyde does not include the particular appropriations that may come separately from PPACA, which establishes its own appropriations. Therefore, the Hyde Amendment does not cover those new and additional funding streams.

Some claimed that there are regulations that HHS must follow that restrict funding for abortion. While that is true, it is true only to the extent that the regulations cover the administration of funds that are part of the annual appropriation covered by the Hyde Amendment. If HHS tries to apply regulatory restrictions based on the Hyde Amendment to funds that are not covered by the Hyde Amendment, Planned Parenthood or the National Abortion Rights Action League (will challenge that application of those rules in court); and they will very likely win. So even if the administration were willing to apply the Hyde-based regulations to funds not covered by Hyde (and it is far from clear that that willingness is present now) the administration is not the ultimate decision maker-it will be the courts, driven by private litigants.

Others claim that, while it may be true that Hyde and its regulations do not apply to non-Hyde funds, the new PPACA appropriations will be commingled with Hyde restricted funds; and once they are mixed, the Hyde restriction applies to all of them. This is wishful think- 
ing. There is no general rule that the commingling of Hyde-restricted and non-Hyde-restricted funds will result in the Hyde-restriction of all such funds. There are accountants who can keep track of the money perfectly well and apply the different restrictions to the different funds, even if they are in some sense commingled.

There is language in the annual Hyde Amendment indicating that, under certain limited circumstances, the restrictions associated with Hyde can be extended to other funds. But there are at least two problems with this argument.

The first is that the Hyde-restricted funds must be appropriated to the unrestricted funds. This would require having a pool of unrestricted funds-here, PPACA funds-just lying around, and then Hyde-restricted funds are somehow combined with them. But that is not the structure here. One can imagine someone with a little eyedropper full of Hyderestricted funds going around and, so to speak, poisoning all those unrestricted wells, in order to restrict all of them. But that is not the way these funds are structured under the statute. There is no reason to believe that there is administrative discretion that allows for that kind of an arrangement, and nobody has come forward to describe how there might be.

Second, there is the question of whether the combination occurs in a "trust fund" within the meaning of the Hyde Amendment. So under certain limited circumstances comingling could make a difference, but those circumstances are not present under PPACA and its appropriations. $^{8}$

Still others suggest that the executive order might fix the funding problem. You may recall that Congressman Stupak held the line in opposing abortion funding, and then at the last minute said, "So long as we have this executive order, we're set. No problem." But there is a problem, and it is the separation of powers under the U.S Constitution. It assigns to the legislative branch the power only to pass laws, not to execute them; and it assigns to the executive branch the power only to faithfully execute the laws, not to pass them. So basically, that means the president cannot arrogate to himself the role of the legislature and cannot override or contradict legislative mandates.

In this context, the language of the Stupak Amendment was raised and passed in the House, but then it was rejected specifically in the Senate. So for the executive to turn around and say, "Well, Congress really meant to have it in there after all, and that's the way we're going to construe it," would violate the Constitution. As with the comingling question, even a willing administration would be challenged in court and would very likely lose, because they would be exceeding their authority as the executive branch. The administration cannot step beyond what the statute authorizes. It cannot do things in contradiction to the statute-which, as you recall, contains broad language that will be 
construed by courts as requiring the funding of abortion. That statutory mandate simply cannot be overturned by executive order-it is beyond the power of the executive branch to do that. ${ }^{9}$

\section{Problems Already Emerging}

As with the conscience problems under PPACA, we have already seen the abortion funding problem begin to materialize, arising in what is called the "high-risk pool." The "high risk" at issue is the high risk of not being able to get coverage. Under this part of the statute, the states develop a plan for temporarily covering those at risk of being uninsurable, they propose their plan to HHS, and if HHS approves, it gets subsidized by the federal government. The idea here is to provide a transition for people who will have a hard time getting coverage because they have preexisting conditions between now and 2014, when preexisting conditions will no longer be a barrier to obtaining coverage.

In concept, the USCCB has no objection to this sort of coverage, which seems entirely sensible. But what happened is that three statesNew Mexico, Maryland, and Pennsylvania-submitted proposals for high risk pools to HHS for approval, and the coverage included abortion. HHS received these plans and approved them.

Folks in the pro-life community cried foul immediately, because they had foreseen the problem and so were waiting to see when it was going to materialize. When they first raised the complaint, HHS responded dismissively, claiming it was another false claim that the statute subsidized abortion coverage. But soon they changed their tune, because they recognized that the plans did indeed include the funding of abortion coverage and had indeed been given HHS approval. ${ }^{10}$

Once HHS realized they actually did have a problem on their hands, the secretary issued a statement pledging that the programs will not fund abortions. But it is one thing for the HHS secretary to say something; it is quite another thing for that to have legal effect. There is no PPACA-wide prohibition on abortion funding, or even a PPACA-wide authorization to the HHS secretary to carve out abortion funding. But as luck would have it, in this particular section of the vast PPACA statute, the secretary is generally given authority to impose any other terms or provisions on "high-risk pool" proposals as the secretary shall see fit. This general kind of authorization affords the secretary some elbow room to exercise discretion.

This action of the secretary may still be susceptible to challenge. Planned Parenthood and the like may still come into court and claim that, although the secretary may have some general authority to impose limits on high-risk pools, that authority does not extend that far. Maybe they will win; maybe they will lose, but at least they have a credible argument. But that stands in contrast with the rest of the statute. This little provision in this little program may give the secretary the authority to 
restrict abortion funding just within this program, but it does not appear anywhere else, or apply anywhere else, in the statute. So if a problem like this were to crop up somewhere else-for example, in the community health centers, with billions of dollars at stake-the secretary will have no authority whatsoever to forbid the funding.

So, when the secretary came out with that statement, we said, "Thank you, Madame Secretary," but we also indicated that it was the first instance of a broader problem of various new appropriations without corresponding new limits on abortion funding, validating the concern we have raised from the beginning. ${ }^{11}$

Consider the fact that the three states, who have their own attorneys, thought that they were authorized to fund abortion. They sent their proposals to HHS, whose lawyers also agreed with that same legal assessment, and initially approved the plans including the funding. It was only after an uproar that anything was done to correct the problem. Additional administrative action was required; and without it, abortion would have been funded. The statute and the executive order are not enough alone to block abortion funding. If the statute and the executive order were enough, the secretary's statement would not have been necessary. The statute and the executive order standing alone do indeed fund abortions. The particular HHS action in this particular program context did have at least some statutory basis. But there is no such basis for the executive order or for similar action by the secretary elsewhere in the act.

When this issue about high-risk pools came up, some legislators went to the Congressional Research Service, which is a credible source, and they asked whether, for high-risk pools, there is anything in the statute that forbids abortion funding and whether there is anything in the executive order that forbids abortion funding. The Congressional Research Service came back with the answer, "No."12 They did not address whether the additional administrative action by the secretary pursuant to the slush category was valid. But the fact that this action was needed underscored that the statute and the executive order by themselves are not enough.

\section{The Roles of Lawyers, Analysts, and Bishops}

In light of the foregoing, it is worthwhile to reflect on the roles of lawyers and policy analysts, particularly in relation to bishops. One might ask if these lawyers and analysts, in their reading of this statute, are trying to exalt themselves to the effect that, because they work for the U.S. bishops, they are special, and their legal analysis deserves special deference.

I have never made that argument, and I never would. None of my colleagues have ever made that argument, and they never would. We should get fired if we ever did. We are no more legally correct by virtue 
of the fact that we work for bishops. Our job is to provide our best educated guess about how the law will actually operate in the future. Then the role of bishops is to say, "Is that operation morally acceptable or unacceptable?" That is the division of labor. We lawyers and analysts are not making any proclamations on our own about whether the law is moral or immoral. Because we are Catholics and, we hope, reasonably well-formed, we have some sense of where the bishops are going to come out on those moral questions, but that is a secondary issue. That is not our professional job, and that is not any part of our legal analysis. It is ultimately a question for the bishops on the moral side of the equation. How the law operates is the object of the moral analysis; it is not the moral analysis itself. The bishops do the moral analysis.

Despite this, there has been a suggestion that the lawyers have overreached. But there has also been the suggestion that the bishops have overreached. Are the bishops not getting into the knitting of the laity-of legislators, of medical professionals, of people who know how these systems tend to work? What business do the bishops have opining on complex and technical laws like PPACA?

It is certainly true that a lawyer who becomes a bishop is not made a better lawyer by virtue of Holy Orders. In any event, most bishops are not civil lawyers-it is not part of the job description. Their job is to teach, sanctify, and govern, not to engage in legal analysis. They have no special authority to analyze a law of any kind, least of all a complex health-care law.

But what they do have the authority-indeed, the duty-to do is to evaluate those laws morally. That authority and responsibility is not limited to simple laws, such as laws against murder. A law against murder is a morally good law. Repealing laws against murder is morally bad. It is straightforward, and everybody agrees. Bishops operate well, and beyond any reasonable dispute, in that simple situation. But that is not the only place they have responsibilities. They are also responsible for situations that are more complex.

Where it is more complex or contested or ambiguous-as with a big regulatory scheme such as health-care reform-there certainly is a difference, but the difference is an additional layer to account for the uncertainty. They are not asking the simple, straightforward question, "Is abortion funding morally wrong?" When the law is clear and it clearly provides for abortion funding, then the moral answer is straightforward as well-yes, it is morally wrong.

What the bishops have to evaluate is a possibility-a risk-of abortion funding. They are taking the moral weight not of a certainty, but of a possibility. In this instance, there is uncertainty about what the law does. We lawyers and analysts are not saying we know exactly what is going to happen, but we are saying that there is a very high probability of this or that particular outcome. The lawyer's enterprise, particularly 
before a law goes into effect, is inherently predictive. There is an irreducible, probabilistic dimension to the legal analysis, so what the bishops had to evaluate was a probability, not a certainty. The question was not, "Is a law that certainly funds abortion morally acceptable?" The answer to that question was always clear, but it was not the one presented here. Instead it was, "Is a law that may fund of abortion morally acceptable?" Or even more precisely, "How great a risk of abortion funding renders a law morally unacceptable?”

One analogy is Russian roulette. It is plainly immoral to shoot yourself in the head; it is also plainly immoral to take a one in six chance that you will shoot yourself in the head. It is not any less the role of a bishop to declare Russian roulette immoral because there is some probabilistic dimension to it. It is certainly immoral to take a one in six chance with your life; the uncertainty associated with the element of chance does not diminish the certainty of the moral judgment. The mere fact that there is a probability involved does not remove the matter from the moral concern of a bishop. So yes, there is uncertainty; but no, the uncertainty does not move the issue outside a bishop's competence or authority.

\section{Morally Unacceptable Risk}

Within that framework, what happened in this instance? I am wary of getting in over my head in terms of doing a moral analysis, so I share these reflections merely as a layperson and a lawyer trying to make sense of what he saw happening around him. And the best I can make of it is this: The bishops set a very high threshold for the amount of legal risk that was morally acceptable.

To begin with, they certainly did not think or speak in terms of precise numerical probabilities. They did not say, for example, if anyone can show us that there is only a 20 percent chance of abortion funding, everything will be fine, but a 25 percent chance is too high. They did, however, seem to require a very high level of confidence that there would be no abortion funding before they could declare the bill morally acceptable.

I think legal rather than statistical language provides a closer approximation to their thinking. The bishops seemed to be saying that the proponents of the bill bear the burden to prove to the bishops' satisfaction that this law will not fund abortion. In addition, proponents must prove it at a level of probability far beyond what we lawyers might call "preponderance of the evidence," or a fifty-fifty chance. To indulge further in the legalese, the bishops seemed to be demanding proof even beyond "clear and convincing evidence" (something on the order of two out of three or three out of four). It seemed to me they were demanding something closer to the criminal conviction standard, which is proof "beyond a reasonable doubt." They needed a very high level of proof that 
there would be no abortion funding. While no one used these terms with me to describe these probabilities, this is how I have been able to make some sense of the situation, stuck as I am with a lawyer's perspective.

An advocate of the bill might say, "If the bishops are saying 'beyond a reasonable doubt,' that is just too strict, too high a standard." But it seems to me that to disagree with the bishops on that question is to disagree in an area where their authority is unmistakable. The bishops are the ones who get to set the moral standard. If you do not like the standard, then you are disagreeing with the bishops in the bishops' realm; you are not disagreeing with the bishops in the realm of the laity, who are principally responsible for temporal affairs. The bishops get to locate the goal post. If the goal post is too far away, too high, or whatever the complaint may be, it should not be miscast as a disagreement over legal technicalities or policy expertise.

Within this overall framework, the bishops heard extensive arguments on both sides-not just from their in-house lawyers and analysts at the USCCB, but from the public debate at large-and they found the level of risk unacceptable.

The USCCB lawyers and analysts (and others) were saying that they considered abortion funding likely. To return to the Russian-roulette analogy, we were identifying something like a five out of six chance that abortion will be funded. We were not saying six out of six-we are only human, and we know cannot predict the future-but five out of six. And we were not making this prediction as a bald assertion, but instead we were providing reasons upon reasons for our conclusions, because we are accountable to the bishops and did not want to steer them in the wrong direction. We knew there is a lot at stake for them, for the Church, and for each of us as Catholics and as citizens; so we want to be transparent about it.

On the other side of the ledger, there were not so many analyses. There were a lot of people making bald assertions to the effect that the law simply did not fund abortion. There were also plenty of ad hominem attacks, usually accusing the bishops of being mere tools of the Republican Party. That charge was especially implausible, because, apart from these particular moral questions, the bishops were generally pushing for health-care reform including universal coverage, squarely against what the Republican Party wanted.

In the few cases when people did provide analyses, they were sparse, they did not provide many reasons, and they did not engage with our arguments. They were talking past us. This was especially frustrating, because we genuinely wanted to hear counter-arguments, because we did not want to get it wrong. If we get strong counter-arguments, we can refine our views to the extent we are wrong.

At the end of the day the bishops looked at this fracas going on, and they seemed to me to have said, “We don't know exactly who's right, but we can tell you we do not have sufficient confidence that this law does 
not fund abortion to declare it morally acceptable." Consider again the Russian-roulette analogy. Conference staff and others were saying that there were five bullets in six chambers. Even if others were more nearly correct-say, that there was just one bullet in six chambers, or if you draw the average, and there were three out of six-that probability of abortion funding was still too high to be morally acceptable. Put in other terms, if our probabilistic legal analysis had been more optimisticfifty-fifty chance of abortion funding, or even one in six-I would have been stunned if the bishops would have found that level of risk morally acceptable.

Put in still other terms, even if the lawyers were wrong, the bishops were right. Ultimately, the moral analysis did not hinge on the differences in legal analysis. The legal dispute was occurring within a range of probabilities so far below anything that might have potentially satisfied the bishops from a moral standpoint that it was not even a close call. Again, I hasten to add that it was not even close morally not because we are sure our legal analysis was perfect, but instead because the level of certainty the bishops required was so high, that the degree of dispute left the question well below that high level.

Consider a football analogy. If we want to give our opponents in this debate the benefit of the doubt, we might say we were all fighting over the fifty-yard line. I actually do not think we were fighting over the fifty-yard line; I think their backs were up against their own goal line. But let us accept for the sake of discussion that we had argued the matter to equipoise. Here is the problem: the fight is not over who crosses the fifty-yard line, but instead-as the bishops have prescribed, because it is their role to set the moral standard-it is over who crosses the goal line. Our opponents are not even in field goal range. And the bishops seemed to be saying, even if you were within field goal range, that is not enough either-they insist that you actually have to cross the goal line. And because-at most-the teams were fighting over the fifty, those pushing for the law are not even close.

So in sum, the bishops are not playing lawyer; we lawyers are not playing bishop.

I conclude by noting that this is not the time for Office of General Counsel lawyers to be backing away from our legal analysis. We have no reason at all to do that. As time has passed our analysis has only been confirmed. When I say that it does not really matter whether the lawyers were right, it is not because I think we were actually not right. Instead, the point is that, even if PPACA never ends up funding a single abortion, it remains that, at the time that the bishops were making the decision, they did not have before them evidence sufficient to give them confidence to say that the risks posed by this law are morally acceptable. They exercised their authority as moral decision makers in their proper realm; and, at least based on the information before them regarding the level of risk, they got the moral decision right. 


\section{Notes}

${ }^{1}$ As the Food and Drug Administration's (FDA's) own medical advisers explained long ago, "The oral contraceptives present society with problems unique in the history of human therapeutics. Never will so many people have taken such potent drugs voluntarily over such a protracted period for an objective other than for control of disease." U.S. Food and Drug Administration, Advisory Committee on Obstetrics and Gynecology, Report on the Oral Contraceptives 1 (1966).

${ }^{2}$ Though disturbing, this incentive is not unforeseen. See Humanae vitae, n. 17: "Who will blame a government which in its attempt to resolve the problems affecting an entire country resorts to the same measures as are regarded as lawful by married people in the solution of a particular family difficulty? Who will prevent public authorities from favoring those contraceptive methods which they consider more effective?"

${ }^{3}$ Among the USCCB's various efforts to highlight the threats to conscience posed by PPACA before it passed, see, e.g., USCCB, "The Need for Conscience Protection," fact sheet, January 26, 2010, http://old.usccb.org/healthcare/Factsheet-conscience-protection-HCR.pdf. The issue was raised again soon after passage in various ways as well. See, e.g., USCCB, Office of General Counsel, "Legal Analysis of the Provisions of the Patient Protection and Affordable Care Act and Corresponding Executive Order Regarding Abortion Funding and Conscience Protection" (2010), 7-8, http://www.usccb.org/about/general-counsel/ upload/Healthcare-EO-Memo.pdf.

${ }^{4}$ Among other things, the USCCB filed comments with the Department of Health and Human Services (HHS) in September 2010, http://www.usccb.org/ about/general-counsel/upload/comments-to-hhs-on-preventive-services2010-09.pdf, well before the question of "preventive services" for women was to be decided by HHS, because Planned Parenthood had announced its intention to urge those services (and the corresponding coverage mandate) to include "all forms of FDA-approved contraception," which includes abortifacient drugs.

${ }^{5}$ Since the oral presentation documented in this writing, in July 2011, the IOM recommended that "preventive services" include all FDA-approved forms of contraception, encompassing also sterilization and drugs that can induce abortion. In August 2011, the Department of Health and Human Services adopted that recommendation wholesale. See Federal Register 76 (2011): 46621.

${ }^{6}$ The bishops actively supported the Menendez Amendment in various ways. See, e.g., Cardinal DiNardo, Bishop Wester, and Bishop Murphy to Members of the Senate, December 14, 2009, http://old.usccb.org/healthcare/legalfiveyears. pdf; USCCB, "Support the Menendez Amendment that Stands for Fairness to Legal Immigrants!” action alert, December 14, 2009, http://old.usccb.org/sdwp/ national/2009-12-14-Action_Alert-MenendezAmendment.pdf.

${ }^{7}$ USCCB, Office of General Counsel, "Legal Analysis," 1-4, contains a more formal and detailed account of the reasoning in support of this conclusion. 
${ }^{8}$ Ibid., 3-4, contains a fuller explanation of the legal reasons why the annual Hyde Amendment and corresponding regulations do not-and could not, even with commingling of funds-cover funds appropriated separately by PPACA.

${ }^{9}$ The shortcomings of the executive order in relation to the problem of abortion funding are addressed in greater detail in ibid., 4-6.

${ }^{10}$ Some of the responses were genuinely funny. The state of Pennsylvania, for example, argued that their plan did not cover abortions generally, but only abortions that are legal in the state of Pennsylvania. Unfortunately, since Roe $v$. Wade, pretty much all abortions are legal in the state of Pennsylvania (or in any state).

${ }^{11}$ See USCCB, "Pro-Life Chair Welcomes HHS Exclusion of Abortion from Federal Insurance Program, Calls for Permanent Law," news release, July 15, 2010, http://usccb.org/news/2010/10-142.cfm.

${ }^{12}$ See Mark Newsom and Jon O. Shimabukuro, Congressional Research Service to Senate Committee on Health, Education, Labor, and Pensions, "High-Risk Pools under PPACA and the Coverage of Elective Abortion Services," July 23, 2010. 